\title{
Rice-eating pattern and the risk of metabolic syndrome especially waist circumference in Korean Genome and Epidemiology Study (KoGES)
}

\author{
Younjhin Ahn', Seon-Joo Park', Hye-kyoung Kwack', Mi Kyung Kim², Kwang-Pil Ko ${ }^{3}$ and Sung Soo Kim ${ }^{1 *}$
}

\begin{abstract}
Background: Metabolic syndrome poses a serious health threat in Asian countries. Rice is a staple food in Korea, and carbohydrate intake is associated with the risk of MetS. We hypothesized that various rice-eating patterns in a carbohydrate-based diet would have different effects on the risk of MetS.

Methods: Participants were 26,006 subjects enrolled in the Korean Genome and Epidemiology Study between 2004 and 2006. They were classified into four dietary patterns - white rice, rice with beans, rice with multi-grains, and mixed based on their food frequency questionnaire responses. We compared metabolic risk traits according to the rice-eating patterns.

Results: Nutrients consumption and the presence of MetS risk factors differed according to rice-eating patterns. In men odds ratio(OR) for central obesity was slightly elevated in mixed group(1.18). In women, the risk for central obesity and abnormal fasting glucose were lower in the rice with beans group (adjusted $O R=0.79,0.83$ respectively) and central obesity in rice with multi-grains(adjusted $O R=0.91$ ) than the white rice group. In postmenopausal women, ORs for central obesity (0.78) and abnormal fasting glucose (0.75) in the rice with beans group and ORs for central obesity (0.83), abnormal HDL-cholesterol (0.87) and MetS(0.85) in the rice with multi-grains group was lower than those in white rice group. In premenopausal women, the risk for central obesity $(\mathrm{OR}=0.77)$ was reduced in the rice with beans group.
\end{abstract}

Conclusion: The risk for MetS was lower in the rice with beans and rice with multi-grains groups compared with the white rice group, particularly in postmenopausal women.

Keywords: Rice, Beans, Multi-grains, Metabolic syndrome (MetS), Postmenopausal women

\section{Background}

Metabolic syndrome (MetS) is characterized by a combination of disturbed glucose and insulin metabolism, central obesity, dyslipidemia, and hypertension [1]. MetS is a risk factor for type 2 diabetes and cardiovascular disease [1-4] and presents a serious health threat that is on the rise in Western and Asian countries [5-7]. The prevalence of MetS has been reported to be $34 \%$ among adults aged 20 years and over in the United States [8], and $32.5 \%$ for men and $31.8 \%$ for women over 30 years of age in Korea [9]. The cause of MetS is unclear but it

\footnotetext{
* Correspondence: ksungsoo@korea.kr

'Division of Epidemiology and Health Index, Center for Genome Science, National Institute of Health, Center for Disease Control and Prevention, Chungcheongbuk-do, South Korea

Full list of author information is available at the end of the article
}

of the article is thought to be associated with genetic, environmental, and dietary factors [10-14].

The amount of carbohydrate intake affects blood glucose and insulin. Furthermore, the quality of the carbohydrate determined by the composition of diet is associated with metabolic consequences. Several studies have reported associations between dietary carbohydrate quality/quantity and lipid profile [15], risk of diabetes [16], and insulin action [11].

Koreans consume $306.58 \mathrm{~g}$ of carbohydrate, which contributes $63.4 \%$ of their total daily energy consumption in 2005 [9]. The main source of carbohydrate is rice. Koreans consume rice two or three times a day as a staple food and it supplies $37.9 \%$ of their total energy

Ciomed Central

(c) 2013 Ahn et al.; licensee BioMed Central Ltd. This is an Open Access article distributed under the terms of the Creative Commons Attribution License (http://creativecommons.org/licenses/by/2.0), which permits unrestricted use, distribution, and reproduction in any medium, provided the original work is properly cited. 
consumption [9]. White rice is usually cooked alone or together with beans and multi-grains in Korea.

In the present study, to determine whether various rice-eating patterns in a carbohydrate-based diet would have different effects on the risk of MetS, we compared the metabolic risk traits according to rice-eating patterns classified using the food frequency questionnaire (FFQ) data collected in the Korean Genome and Epidemiology Study (KoGES), a large population-based cohort study of Koreans.

\section{Methods}

\section{Subjects}

The Korean Genome and Epidemiology Study (KoGES) was launched in 2001 with a population based cohort of 2 cities each in rural and urban area of central part of Korea. The main objectives of this study were to establish national genomic cohort and to examine causal relationship between the genetic and environmental factors associated with major diseases such as diabetes mellitus, hypertension, obesity, and MetS in Korea. The size and scope of the project were gradually expanded and it encompasses 7 cohort studies mainly targeting 40 to 69 years age group. KoGES has recruited more than 240,000 participants by the end of 2011. The written informed consent was obtained from each participant.

We analyzed data of participants who joined KoGES between November 2004 and December 2006 in this study. Of those, 40,254 subjects had available dietary data of food frequency questionnaire (FFQ). The records with extremely low or high energy intake $(<800$ or $>4,000 \mathrm{kcal}$ for men and $<500$ or $>3,500 \mathrm{kcal}$ for women) were excluded $(n=978)$.

Subjects with previous diagnosed hypertension, hyperlipidemia, diabetes mellitus, or cancer (any type) were excluded from the study $(n=11,842)$ because of the possibility of dietary habit change after diagnosis. Subjects with no waist circumference, triglyceride, high-density lipoprotein (HDL) cholesterol, blood pressure (BP), or fasting glucose data $(n=1,428)$ were further excluded from our study. Finally, 26,006 subjects were included for the analysis of this study.

\section{Data collection}

Participants were recruited in 28 health examination centers across the country (Chonbuk National University Hospital, Chonnam National University Hospital, Chunchoen Sacred Heart Hospital, Daegu Catholic University Medical Center, Dankook University Hospital, Dobong-Gu Health Center, Dong-A University Medical Center, Ehwa Womans University Mokdong Hospital, Gangdong Health Center, Gimje Public Health Center, Green Hospital, Gyeongju Health Center, Hallym University Sacred Heart Hospital, Inha University
Hospital, Inje University Sanggye Paik Hospital, Jechoen Public Health Center, Jungnang Health Center, JungwonGu Health Center, Kangbuk Samsung Hospital, Konkuk University Chungju Hospital, Korea University Ansan Hospital,Kosin University Gospel Hospital, Kyungpook National University Hospital, Seongbuk Health Center, Sujeong-Gu Health Center, Ulsan University Hospital, Yeoncheon-Gun Health Center and County Hospital, Yonsei University Hospital Occupational Health Center). They originally visited for their health check-up and voluntarily agreed to participate in the KoGES. Questionnaires including age, gender, education level $(<=6$ years, 7-12 years, 12 years <), smoking status (never/ex-/ current), drinking status (non/ex-/current), dietary supplement use (yes/no), regular exercise (yes/no), and menopause status (yes/no) and FFQ were administered by trained interviewers.

Blood pressures (BPs) and anthropometric measurement were obtained by trained personnel. Waist circumference was measured midway between the inferior margin of last rib and crest of the ilium in a horizontal plane in $0.1 \mathrm{~cm}$ unit. Blood pressures were measured by a trained technician using a mercury sphygmomanometer. Subjects had 10 minutes resting before taking the $\mathrm{BP}$ measurements. Two readings were taken on the subject's dominant arm while in the sitting position with a 5 -minute interval between readings. The BP values reported here are the mean of the two measurements.

Participants were asked to fast more than 8 hours before examination and fast venous blood samples were drawn at study site. Fasting glucose, triglycerides, and HDL cholesterol were assessed using a 7600-210 automatic analyzer (Hitachi, Tokyo, Japan).

\section{Dietary data}

Dietary intake was assessed using the 103-item FFQ (Additional file 1: Appendix 1). The development and validation of the questionnaire has been described in previous reports $[17,18]$. Briefly, the FFQ was designed using dietary data obtained from the Korea Health and Nutrition Examination Survey (KHANES) 24-h recall data in 1998. Food items were selected using a databased approach, and several seasonal foods were added to the final food list.

The frequency of servings was classified into nine categories: never or seldom, once a month, two or three times a month, one or two times a week, three or four times a week, five or six times a week, once a day, twice a day, or three times or more a day. The portion size was categorized as small, medium, or large. Participants were requested to answer the length of time they used seasonal food items as $3,6,9$, or 12 months. The FFQ has been validated in 124 subjects using a 12-day diet record. 
The nutrient intake from each food item in the FFQ was determined by the weight derived from the consumption frequency and portion size of each food item. The daily nutrient intake of each individual was calculated as the sum of the nutrient intake from each food item. The nutrient and isoflavone compositions used in the calculation were based on the Food Composition Table $[19,20]$.

Glycemic load was calculated by multiplying carbohydrate content of each food item, which was based on the reported consumption frequency and portion size by its glycemic index. The glycemic load value for one day was calculated as the sum of all food items. The overall dietary glycemic index was calculated by dividing the average daily glycemic load by the average daily carbohydrate intake. The glycemic index value for each food item was obtained from the International Tables of Glycemic Index [21], the online Glycemic Index Database maintained by the University of Sydney [22], and a previous report that listed the glycemic index of Korean foods [23]. The reference of glycemic index values was glucose (glycemic index for glucose $=100$ ).

\section{Classification of subjects}

Total of 26,006 subjects were included for analysis and classified into four groups according to their response on the rice-eating pattern. Before asking consumption frequency and amount of cooked rice, we asked 'What kind of cooked rice do you usually eat? (white rice only/rice with other foods/mix two types)' and then 'What kind of foods do you mainly eat cooked rice with? (beans/multigrains)' Rice-eating patterns were defined as 'eating white rice group' $(n=6,136)$, 'eating rice with beans' $(n=2,589)$, 'eating rice with multi-grains' $(n=12,440)$, and 'eating rice in mixed' ( $n=4,841)$.

MetS was defined by the presence of three or more of the following five components according the Adult Treatment Panel using waist circumference for Asians $[24,25]$ : central obesity ( $\geq 90 \mathrm{~cm}$ for men or $\geq 80 \mathrm{~cm}$ for women); reduced HDL cholesterol $(<40 \mathrm{mg} / \mathrm{dL}$ for men or $<50 \mathrm{mg} / \mathrm{dL}$ for women); hypertriglyceridemia as defined by an elevated triglyceride level $(\geq 150 \mathrm{mg} / \mathrm{dL})$; elevated BP as defined by systolic blood pressure (SBP) $\geq$ $130 \mathrm{mmHg}$ or diastolic blood pressure $(\mathrm{DBP}) \geq 85$ $\mathrm{mmHg}$; and raised fasting glucose $(\geq 100 \mathrm{mg} / \mathrm{dL})$.

Smokers were defined as having smoked at least 400 cigarettes during their lifetime and divided into currentor ex-smokers based on their current smoking status. Drinkers were classified as drinkers or ex-drinkers in terms of current alcohol intake, and nondrinker was defined as being unable or unwilling to drink during their lifetime. Subjects who reported using any dietary supplements were classified as supplement users. Subjects were classified as regular exercisers or not if they answered to do exercise until sweaty regularly.

\section{Statistical analysis}

General/metabolic characteristics and nutrients intake are expressed as the means \pm standard deviations (SD) for continuous variables and as frequencies or percentages for categorical variables. The effect of the riceeating patterns was assessed using analysis of variance (ANOVA) for continuous variables and chi-square test for categorical variables. Multiple comparisons of the mean were performed using Scheffe's test. Triglyceride, HDL cholesterol, BP, and fasting serum glucose were log-transformed to improve normality.

The relationships between rice-eating patterns and MetS were examined using logistic regression. Odds ratios (ORs) and 95\% confidence intervals (CIs) were calculated. Adjustments were made for age, total energy intake, education level, supplement use, exercise, drinking, and smoking. We analyzed the effects of rice-eating patterns by gender because the prevalence of MetS and reported risk factors differ by gender.

All statistical analyses were performed using SAS v9.13 (SAS Institute Inc., Cary, NC, USA) and a $P$-value of 0.05 was considered to be statistically significant.

The design of study was reviewed and approved by the Institutional Review Board of Korea Centers for Disease Control and Prevention.

\section{Results}

Characteristics of the participants according to their rice-eating patterns are shown in Table 1 . The mean age of men was highest in the rice with beans group (54.9 years old). The 35 to 44 year-old participants ate more white rice alone and 45 to 54 year-old participants were more distributed in mixed group. Over 55 year-old men were more abundant in rice with beans group. Higher proportions of current smokers, drinkers, people who did not take supplements and did not exercise were observed in white rice group. The habits of participants in the rice with beans and rice with multi-grains groups were healthier than those of participants in the white rice group. Similar to the finding for men, the mean age of the women in the rice with beans group was older than those of the other groups (51.8 years). Younger ( $<55$ years) participants were in mixed group and older participants were in rice with beans group. The proportion of participants who exercised was higher in the rice with multi-grains groups and the proportion of dietary supplements eaters was higher in mixed group than in the white rice-alone group. The proportion of postmenopausal women was higher in rice with beans group.

MetS component variables were compared according to rice-eating patterns. Means of WC and SBP in men 
Table 1 Participants' characteristics according to rice-eating patterns

\begin{tabular}{|c|c|c|c|c|c|c|}
\hline & \multirow{2}{*}{$\begin{array}{c}\text { Total } \\
(n=26,006)\end{array}$} & \multirow{2}{*}{$\begin{array}{l}\text { White rice group } \\
\quad(n=6,136)\end{array}$} & \multicolumn{2}{|c|}{ Rice with other foods group } & \multirow{2}{*}{$\begin{array}{c}\text { Mixed group } \\
(n=4,841)\end{array}$} & \multirow[t]{2}{*}{$P$} \\
\hline & & & $\begin{array}{l}\text { Rice with beans } \\
\quad(n=2,589)\end{array}$ & $\begin{array}{l}\text { Rice with multi-grains } \\
(n=12,440)\end{array}$ & & \\
\hline \multicolumn{7}{|l|}{ Men } \\
\hline No. of subjects & 7,561 & 2,386 & 699 & 2,991 & 1,485 & \\
\hline \multicolumn{7}{|l|}{ Age (years) } \\
\hline mean $\pm S D$ & $52.2 \pm 8.8$ & $50.6 \pm 8.7^{c}$ & $54.9 \pm 9.1^{a}$ & $53.3 \pm 8.8^{b}$ & $51.1 \pm 8.0^{c}$ & $<0.0225$ \\
\hline \multicolumn{7}{|l|}{ Age group, years, $n(\%)$} \\
\hline $35-44$ & $1,728(22.9)$ & $711(29.8)$ & $97(13.9)$ & $561(18.8)$ & $359(24.2)$ & $<0.0001$ \\
\hline $45-54$ & 2,997 (39.6) & $940(39.4)$ & $253(36.2)$ & $1,150(38.4)$ & $654(44.0)$ & \\
\hline $55-64$ & $2,029(26.8)$ & $545(22.8)$ & $216(30.9)$ & $889(29.7)$ & $379(25.5)$ & \\
\hline $64-75$ & $807(10.7)$ & $190(8.0)$ & $133(19.0)$ & $391(13.1)$ & $93(6.3)$ & \\
\hline \multicolumn{7}{|l|}{ Education levels, years, $n(\%)$} \\
\hline$<=6$ & $2,186(29.5)$ & $708(30.2)$ & $245(35.8)$ & $905(30.8)$ & $328(22.7)$ & $<0.0001$ \\
\hline $7 \sim 12$ & $2,843(38.4)$ & $900(38.5)$ & $260(37.9)$ & $1,143(38.8)$ & $540(37.4)$ & \\
\hline $12<$ & $576(32.1)$ & $733(31.3)$ & $180(26.3)$ & $894(30.4)$ & $576(39.9)$ & \\
\hline \multicolumn{7}{|l|}{ Smoking status, $n(\%)$} \\
\hline Nonsmoker & $2,250(29.9)$ & $674(28.3)$ & $224(32.2)$ & $921(30.9)$ & $431(29.2)$ & $<0.0001$ \\
\hline Ex-smoker & $2,829(37.5)$ & $825(34.7)$ & $276(39.7)$ & 1,151 (38.6) & $577(39.0)$ & \\
\hline Current smoker & $2,457(32.6)$ & $880(37.0)$ & $195(28.1)$ & $912(30.5)$ & $470(31.8)$ & \\
\hline \multicolumn{7}{|l|}{ Drinking status, $n$ (\%) } \\
\hline Nondrinker & $1,522(20.2)$ & $443(18.6)$ & $163(23.4)$ & $639(21.4)$ & $277(18.7)$ & 0.0108 \\
\hline Ex-drinker & $552(7.3)$ & $161(6.8)$ & $48(6.9)$ & $235(7.9)$ & $108(7.3)$ & \\
\hline Current drinker & $5,456(72.5)$ & $1,771(74.6)$ & $486(69.7)$ & $2,105(70.7)$ & $1,094(74.0)$ & \\
\hline \multicolumn{7}{|l|}{ Exercise, $n$ (\%) } \\
\hline No & $3,648(48.4)$ & $1,334(56.5)$ & $319(45.7)$ & $1,305(43.7)$ & $680(45.9)$ & $<0.0001$ \\
\hline Yes & 3,895 (51.6) & $1,035(43.5)$ & $379(54.3)$ & $1.679(56.3)$ & $802(54.1)$ & \\
\hline \multicolumn{7}{|l|}{ Supplement use, $n$ (\%) } \\
\hline No & $5,407(71.7)$ & $1,847(77.8)$ & $478(68.5)$ & $2,059(68.9)$ & $1,023(69.1)$ & $<0.0001$ \\
\hline Yes & $2,132(28.3)$ & $526(22.2)$ & $220(31.5)$ & $929(31.1)$ & $457(30.9)$ & \\
\hline Waist circumference $(\mathrm{cm})$ & $85.4 \pm 7.3$ & $85.1 \pm 7.4^{b}$ & $84.9 \pm 7.5^{b}$ & $85.6 \pm 7.3^{a b}$ & $86.0 \pm 7.3^{a}$ & 0.0004 \\
\hline Triglyceride (mg/dL) & $149.6 \pm 108.8$ & $150.4 \pm 105.6$ & $155.3 \pm 121.1$ & $148.4 \pm 108.3$ & $148.2 \pm 108.8$ & \\
\hline HDL cholesterol (mg/dL) & $52.8 \pm 12.3$ & $52.8 \pm 12.3$ & $52.7 \pm 12.0$ & $52.9 \pm 12.2$ & $52.9 \pm 12.4$ & \\
\hline SBP $(\mathrm{mmHg})$ & $124.8 \pm 15.3$ & $124.3 \pm 15.1^{b}$ & $126.3 \pm 16.2^{\mathrm{a}}$ & $125.1 \pm 15.4^{\mathrm{ab}}$ & $124.4 \pm 14.9^{a b}$ & 0.0122 \\
\hline $\mathrm{DBP}(\mathrm{mmHg})$ & $78.6 \pm 10.0$ & $78.4 \pm 9.7$ & $79.2 \pm 10.7$ & $78.6 \pm 10.0$ & $78.5 \pm 9.9$ & \\
\hline Fasting glucose (mg/dL) & $95.0 \pm 18.9$ & $94.5 \pm 18.3$ & $95.4 \pm 17.6$ & $95.4 \pm 18.5$ & $95.0 \pm 21.2$ & \\
\hline No. of subjects with MetS (\%) & $1,486(19.4)$ & $454(19.0)$ & $136(19.5)$ & $594(19.9)$ & 284(19.1) & \\
\hline \multicolumn{7}{|l|}{ Women } \\
\hline No. of subjects & 18,445 & 3,750 & 1,890 & 9,449 & 3,356 & \\
\hline \multicolumn{7}{|l|}{ Age (years) } \\
\hline mean $\pm S D$ & $50.4 \pm 7.7$ & $49.6 \pm 7.7^{c}$ & $51.8 \pm 7.7^{\mathrm{a}}$ & $50.7 \pm 7.7^{b}$ & $49.6 \pm 7.3^{c}$ & $<0.0001$ \\
\hline \multicolumn{7}{|l|}{ Age group, years, $n(\%)$} \\
\hline $35-44$ & $4,621(25.1)$ & $1,089(29.0)$ & $364(19.2)$ & $2,248(23.8)$ & $920(27.4)$ & $<0.0001$ \\
\hline $45-54$ & $8,840(47.9)$ & $1,759(46.9)$ & $909(48.1)$ & $4,487(47.5)$ & $1,685(50.2)$ & \\
\hline
\end{tabular}


Table 1 Participants' characteristics according to rice-eating patterns (Continued)

\begin{tabular}{|c|c|c|c|c|c|c|}
\hline $55-64$ & $3,917(21.2)$ & $693(18.5)$ & $487(25.8)$ & $2,121(22.4)$ & $616(18.4)$ & \\
\hline $64-75$ & $1,067(5.8)$ & $209(5.6)$ & $130(6.9)$ & $593(6.3)$ & $135(4.0)$ & \\
\hline \multicolumn{7}{|l|}{ Education levels, years, $n$ (\%) } \\
\hline$<=6$ & $7,549(41.9)$ & $1,624(44.4)$ & $867(47.2)$ & $3,824(41.4)$ & $1,234(37.6)$ & \multirow[t]{3}{*}{$<0.0001$} \\
\hline $7 \sim 12$ & $7,356(40.8)$ & $1,426(39.0)$ & $716(39.0)$ & $3,825(41.4)$ & $1,389(42.3)$ & \\
\hline $12<$ & $658(17.3)$ & $607(16.6)$ & $254(13.8)$ & $1,558(17.2)$ & $658(20.1)$ & \\
\hline \multicolumn{7}{|l|}{ Smoking status, $n$ (\%) } \\
\hline Nonsmoker & $17,716(96.7)$ & $3,536(95.2)$ & $1,830(97.3)$ & $9,111(96.9)$ & 3,239 (97.1) & \multirow[t]{3}{*}{$<0.0001$} \\
\hline Ex-smoker & $243(1.3)$ & $65(1.7)$ & $29(1.5)$ & $112(1.2)$ & $37(1.1)$ & \\
\hline Current smoker & $371(2.0)$ & $114(3.1)$ & $22(1.2)$ & $175(1.9)$ & $60(1.8)$ & \\
\hline \multicolumn{7}{|l|}{ Drinking status, $n(\%)$} \\
\hline Nondrinker & $9,428(63.3)$ & $2,288(61.6)$ & $1,271(67.5)$ & $5,923(63.1)$ & $2,023(60.9)$ & \multirow[t]{3}{*}{$<0.0001$} \\
\hline Ex-drinker & $379(2.5)$ & $105(2.8)$ & $50(2.7)$ & $224(2.4)$ & $67(2.9)$ & \\
\hline Current drinker & $5,129(34.2)$ & $1,321(35.6)$ & $562(29.8)$ & $3,246(34.5)$ & $1,207(36.2)$ & \\
\hline \multicolumn{7}{|l|}{ Exercise, $n(\%)$} \\
\hline No & $8,982(48.9)$ & $2,213(59.4)$ & $882(46.8)$ & $4,270(45.4)$ & $1,617(48.3)$ & \multirow[t]{2}{*}{$<0.0001$} \\
\hline Yes & $9,383(51.1)$ & $1,515(40.6)$ & $1,001(53.2)$ & $5.139(54.6)$ & $1,728(51.7)$ & \\
\hline \multicolumn{7}{|l|}{ Supplement use, $n$ (\%) } \\
\hline No & $10,439(56.8)$ & $2,371(63.7)$ & $1,061(56.4)$ & $5,142(54.6)$ & $1,865(55.8)$ & \multirow[t]{2}{*}{$<0.0001$} \\
\hline Yes & $7,926(43.2)$ & $1,355(36.3)$ & $822(43.6)$ & $4,274(45.4)$ & $1,475(44.2)$ & \\
\hline \multicolumn{4}{|l|}{ Menopause, $n(\%)$} & & & \multirow[t]{6}{*}{$<0.0001$} \\
\hline Post- & $8,856(48.0)$ & $1,636(43.6)$ & $1,065(56.4)$ & $4,665(49.4)$ & $1,490(44.4)$ & \\
\hline Pre- & $9,589(52.0)$ & $2,114(56.4)$ & $825(43.6)$ & $4,784(50.6)$ & $1,866(55.6)$ & \\
\hline Waist circumference $(\mathrm{cm})$ & $78.0 \pm 7.8$ & $78.3 \pm 7.8$ & $77.7 \pm 7.5$ & $78.0 \pm 7.8$ & $77.8 \pm 7.9$ & \\
\hline Triglyceride (mg/dL) & $107.7 \pm 70.7$ & $109.0 \pm 72.6$ & $108.9 \pm 69.1$ & $107.9 \pm 71.0$ & $105.2 \pm 68.3$ & \\
\hline HDL cholesterol (mg/dL) & $58.6 \pm 12.7$ & $58.4 \pm 12.8$ & $58.2 \pm 12.5$ & $58.8 \pm 12.8$ & $58.7 \pm 12.5$ & \\
\hline SBP $(\mathrm{mmHg})$ & $118.7 \pm 15.7$ & $118.8 \pm 16.0^{b}$ & $120.2 \pm 15.6^{a}$ & $118.7 \pm 15.7^{b}$ & $117.6 \pm 5.4^{c}$ & $<0.0001$ \\
\hline $\mathrm{DBP}(\mathrm{mmHg})$ & $74.0 \pm 10.0$ & $74.1 \pm 10.1^{\mathrm{ab}}$ & $74.8 \pm 9.9^{a}$ & $74.1 \pm 10.0^{b}$ & $73.2 \pm 9.8^{c}$ & $<0.0001$ \\
\hline Fasting glucose (mg/dL) & $90.6 \pm 16.2$ & $90.8 \pm 14.3$ & $89.8 \pm 13.5$ & $90.7 \pm 15.9$ & $90.1 \pm 20.0$ & \\
\hline No. of subjects with MetS (\%) & 2,999 (16.3) & $625(16.7)$ & $325(17.2)$ & 1,572 (16.6) & $477(14.2)$ & \\
\hline
\end{tabular}

For differences among rice-eating patterns using ANOVA with Scheffé's test for data that are means \pm SDs(continuous variables) and chi-square test for data that are percentages(categorical variables).

and those of SBP and DBP in women were significantly different among groups.

Table 2 shows nutrients consumption among the riceeating pattern groups. The dietary glycemic index was highest in the white rice group. The rice with beans group showed the highest consumption of protein, fiber and total isoflavones intake. Total energy and energy from cooked rice, percentage of energy from cooked rice, carbohydrate intake, and dietary glycemic load were the highest in rice with multi-grains group. Dietary characteristics by rice eating patterns were similar in both genders.

Table 3 shows odds ratios of MetS and component risk factors. In men, the risk for central obesity was maintained after adjustment for several confounding factors (adjusted OR in model $3=1.18$ ) in mixed group. The risk for high $\mathrm{BP}$ was greater in rice with beans $(\mathrm{OR}=$ $1.27)$ and rice with multi-grains $(\mathrm{OR}=1.14)$ groups compared with the white rice group, however, the associations were not significant after adjusting for confounding variables. No other risk factors or MetS were associated with rice-eating patterns. In women, the odds ratios for central obesity and high fasting glucose were significantly lower after adjustment in rice with beans group(adjusted OR in model $3=0.79,0.83$ respectively). The risk for high BP was elevated in the rice with beans and the significance was disappeared after adjustment. 
Table 2 Comparisons of nutrients intake according to gender and rice-eating patterns ${ }^{1}$

\begin{tabular}{|c|c|c|c|c|c|c|c|c|c|c|c|c|c|c|c|}
\hline \multirow[t]{2}{*}{ Nutrient/food group intake } & \multirow{2}{*}{\multicolumn{3}{|c|}{$\begin{array}{c}\text { Total } \\
(n=26,006)\end{array}$}} & \multirow{2}{*}{\multicolumn{3}{|c|}{$\begin{array}{l}\text { White rice group } \\
(n=6,136)\end{array}$}} & \multicolumn{6}{|c|}{ Rice with other foods group } & \multirow{2}{*}{\multicolumn{3}{|c|}{$\begin{array}{l}\text { Mixed group } \\
(n=4,841)\end{array}$}} \\
\hline & & & & & & & \multicolumn{3}{|c|}{$\begin{array}{l}\text { Rice with beans } \\
\quad(n=2,589)\end{array}$} & \multicolumn{3}{|c|}{$\begin{array}{l}\text { Rice with multi-grains } \\
\quad(n=12,440)\end{array}$} & & & \\
\hline \multicolumn{16}{|l|}{$\overline{M e n}$} \\
\hline Total energy (kcal) & 1,920 & \pm & 541.6 & 1,845 & \pm & $536.3^{c}$ & 1,849 & \pm & $504.8^{\mathrm{bc}}$ & 2,001 & \pm & $547.6^{a}$ & 1,911 & \pm & $532.3^{b}$ \\
\hline Energy from cooked rice (kcal) & 1,073 & \pm & 313.7 & 982 & \pm & $284.1^{c}$ & 1,033 & \pm & $288.9^{b}$ & 1,161 & \pm & $320.6^{\mathrm{a}}$ & 1,059 & \pm & $303.7^{b}$ \\
\hline Energy \% from cooked rice (\%) & 57.6 & \pm & 14.8 & 55.1 & \pm & $15.0^{c}$ & 57.4 & \pm & $14.5^{\mathrm{b}}$ & 59.6 & \pm & $14.4^{\mathrm{a}}$ & 57.0 & \pm & $14.3^{b}$ \\
\hline Protein (g) & 63.5 & \pm & 24.0 & 60.7 & \pm & $24.0^{\mathrm{b}}$ & 65.7 & \pm & $21.9^{\mathrm{a}}$ & 65.2 & \pm & $24.1^{\mathrm{a}}$ & 63.3 & \pm & $24.5^{\mathrm{a}}$ \\
\hline Fat (g) & 30.6 & \pm & 17.0 & 30.9 & \pm & 17.3 & 31.9 & \pm & 16.1 & 30.0 & \pm & 16.8 & 30.8 & \pm & 17.2 \\
\hline Carbohydrate (g) & 341.0 & \pm & 92.1 & 324.2 & \pm & $88.9^{c}$ & 319.3 & \pm & $85.0^{c}$ & 360.0 & \pm & $93.8^{\mathrm{a}}$ & 338.1 & \pm & $89.4^{b}$ \\
\hline Fiber (g) & 6.0 & \pm & 2.9 & 5.3 & \pm & $2.8^{d}$ & 7.0 & \pm & $2.8^{\mathrm{a}}$ & 6.4 & \pm & $2.9^{b}$ & 5.8 & \pm & $2.8^{c}$ \\
\hline Glycemic Index & 56.9 & \pm & 3.1 & 57.2 & \pm & $3.2^{\mathrm{a}}$ & 56.1 & \pm & $3.1^{d}$ & 56.9 & \pm & $3.1^{c}$ & 57.0 & \pm & $3.1^{b}$ \\
\hline Glycemic Load & 193.6 & \pm & 51.3 & 184.8 & \pm & $48.9^{b}$ & 178.7 & \pm & $45.9^{c}$ & 204.6 & \pm & $52.4^{\mathrm{a}}$ & 192.7 & \pm & $50.4^{a b}$ \\
\hline Total isoflavones (mg) & 11.5 & \pm & 9.3 & 8.6 & \pm & $7.3^{c}$ & 25.5 & \pm & $9.7^{\mathrm{a}}$ & 11.0 & \pm & $8.3^{b}$ & 11.0 & \pm & $7.9^{b}$ \\
\hline \multicolumn{16}{|l|}{ Women } \\
\hline Total energy (kcal) & 1,742 & \pm & 522.0 & 1,637 & \pm & $509.4^{c}$ & 1,694 & \pm & $515.0^{b}$ & 1,796 & \pm & $524.2^{\mathrm{a}}$ & 1733 & \pm & $511.8^{b}$ \\
\hline Energy from cooked rice (kcal) & 944.0 & \pm & 320.5 & 847.6 & \pm & $281.3^{c}$ & 909.9 & \pm & $299.9^{b}$ & 998.0 & \pm & $332.5^{\mathrm{a}}$ & 919.0 & \pm & $307.0^{b}$ \\
\hline Energy \% from cooked rice (\%) & 55.6 & \pm & 16.2 & 53.9 & \pm & $16.9^{c}$ & 55.3 & \pm & $16.0^{\mathrm{b}}$ & 56.8 & \pm & $16.1^{\mathrm{a}}$ & 54.4 & \pm & $15.8^{b c}$ \\
\hline Protein (g) & 58.4 & \pm & 23.1 & 54.0 & \pm & $22.9^{c}$ & 61.1 & \pm & $22.8^{\mathrm{a}}$ & 59.7 & \pm & $23.1^{\mathrm{a}}$ & 58.1 & \pm & $22.9^{b}$ \\
\hline Fat (g) & 26.3 & \pm & 15.2 & 26.0 & \pm & $16.2^{\mathrm{b}}$ & 27.4 & \pm & $14.1^{\mathrm{a}}$ & 26.1 & \pm & $15.1^{\mathrm{b}}$ & 26.7 & \pm & $14.9^{\mathrm{ab}}$ \\
\hline Carbohydrate (g) & 313.1 & \pm & 91.9 & 292.0 & \pm & $86.7^{c}$ & 297.3 & \pm & $89.9^{c}$ & 325.7 & \pm & $93.0^{\mathrm{a}}$ & 310.5 & \pm & $89.7^{b}$ \\
\hline Fiber (g) & 6.2 & \pm & 3.2 & 5.4 & \pm & $3.0^{d}$ & 7.1 & \pm & $3.2^{\mathrm{a}}$ & 6.4 & \pm & $3.2^{\mathrm{b}}$ & 6.0 & \pm & $3.1^{c}$ \\
\hline Glycemic Index & 56.3 & \pm & 3.6 & 56.7 & \pm & $3.8^{\mathrm{a}}$ & 55.5 & \pm & $3.6^{c}$ & 56.2 & \pm & $3.5^{b}$ & 56.3 & \pm & $3.5^{b}$ \\
\hline Glycemic Load & 176.0 & \pm & 51.0 & 165.2 & \pm & $47.8^{c}$ & 164.5 & \pm & $48.3^{c}$ & 183.0 & \pm & $51.8^{\mathrm{a}}$ & 174.9 & \pm & $49.7^{b}$ \\
\hline Total isoflavones (mg) & 11.8 & \pm & 10.5 & 8.4 & \pm & $8.6^{c}$ & 23.9 & \pm & $11.1^{\mathrm{a}}$ & 11.0 & \pm & $9.7^{\mathrm{b}}$ & 10.8 & \pm & $9.2^{b}$ \\
\hline
\end{tabular}

1. Mean \pm SD.

2. Different alphabet shows that means are significantly different among rice-eating patterns using ANOVA with Scheffé's test for multiple comparisons $(\mathrm{P}<0.05)$.

The ORs for central obesity(adjusted OR in model $3=0.91$ ) and hypertriglycemia (adjusted OR in model $2=0.90$ ) in the rice with multi-grains group with reference to the white rice group were significantly lower after adjustment. The risk for BP was lowered in mixed group and the significance was remained after adjustment (adjusted OR in model=0.86). The OR for MetS in the rice with beans and the rice with multi-grains groups was significantly lower in model 2 (adjusted OR= 0.89 and 0.82 , respectively). The OR for MetS of mixed group showed significantly lower in all models.

Table 4 shows the multivariate adjusted OR for MetS and its components in women by menopause states. Because menopause is associated with increased risk of MetS, and waist circumference is also increased after menopause, we analyze the MetS risks by rice-eating pattern before and after menopause separately. The ORs for central obesity and abnormal glucose control were significantly reduced in rice with beans group, the OR for central obesity in rice with multi-grains group, and the ORs for central obesity, HDL abnormality and MetS in mixed group were lower in postmenopausal women. However, in premenopausal women, the OR for central obesity was reduced only in the rice with beans group.

\section{Discussion}

The present study compared the effect of rice-eating patterns on MetS. We categorized the subjects into four rice-eating groups: white rice alone, rice with beans, rice with multi-grains, and mixed group. We analyzed the effects of rice-eating patterns by gender because the prevalence of MetS and reported risk factors differ by gender $[5,26]$. We found that the risk for metabolic disorders was lower in the rice with beans and rice with multi-grains groups compared with the white rice group, particularly in postmenopausal women. The characteristics such as lifestyle habits, nutrient consumption, and metabolic indices differed according to rice-eating patterns. 
Table 3 Odds ratios $(95 \% \mathrm{Cls})$ for metabolic syndrome and the individual components according to rice-eating patterns and gender

\begin{tabular}{|c|c|c|c|c|c|c|c|}
\hline \multirow{3}{*}{$\begin{array}{l}\text { Metabolic } \\
\text { syndrome traits }\end{array}$} & \multirow{3}{*}{$\begin{array}{l}\text { White rice group } \\
\text { Ref }\end{array}$} & \multicolumn{4}{|c|}{ Rice with other foods group } & \multicolumn{2}{|c|}{ Mixed group } \\
\hline & & \multicolumn{2}{|c|}{ Rice with beans } & \multicolumn{2}{|c|}{ Rice with multi-grains } & \multirow[b]{2}{*}{ OR } & \multirow[b]{2}{*}{$95 \% \mathrm{Cl}$} \\
\hline & & OR & $95 \% \mathrm{Cl}$ & OR & $95 \% \mathrm{Cl}$ & & \\
\hline \multicolumn{8}{|l|}{ Men } \\
\hline \multicolumn{8}{|c|}{ Waist circumference } \\
\hline Model 1 & 1 & 0.97 & $0.80-1.18$ & 1.07 & $0.95-1.21$ & 1.26 & $1.05-1.39$ \\
\hline Model 2 & 1 & 0.93 & $0.77-1.13$ & 1.00 & $0.88-1.13$ & 1.18 & $1.02-1.36$ \\
\hline Model 3 & 1 & 0.91 & $0.75-1.11$ & 0.98 & $0.87-1.12$ & 1.18 & $1.02-1.36$ \\
\hline \multicolumn{8}{|l|}{ Triglyceride } \\
\hline Model 1 & 1 & 0.92 & $0.77-1.10$ & 0.93 & $0.83-1.04$ & 0.98 & $0.86-1.12$ \\
\hline Model 2 & 1 & 1.00 & $0.83-1.19$ & 0.96 & $0.86-1.08$ & 0.98 & $0.86-1.24$ \\
\hline Model 3 & 1 & 1.06 & $0.88-1.27$ & 1.01 & $0.90-1.13$ & 1.02 & $0.89-1.17$ \\
\hline \multicolumn{8}{|l|}{ HDL cholesterol } \\
\hline Model 1 & 1 & 1.15 & $0.91-1.46$ & 0.95 & $0.82-1.12$ & 1.00 & $0.83-1.21$ \\
\hline Model 2 & 1 & 1.12 & $0.89-1.43$ & 0.94 & $0.80-1.10$ & 1.00 & $0.83-1.21$ \\
\hline Model 3 & 1 & 1.13 & $0.89-1.45$ & 0.95 & $0.81-1.12$ & 1.02 & $0.84-1.24$ \\
\hline \multicolumn{8}{|l|}{ Blood pressure } \\
\hline Model 1 & 1 & 1.27 & $1.07-1.51$ & 1.14 & $1.02-1.27$ & 1.04 & $0.91-1.19$ \\
\hline Model 2 & 1 & 1.15 & $0.96-1.36$ & 1.06 & $0.94-1.18$ & 1.03 & $0.90-1.17$ \\
\hline Model 3 & 1 & 1.16 & $0.98-1.38$ & 1.09 & $0.97-1.22$ & 1.08 & $0.94-1.24$ \\
\hline \multicolumn{8}{|l|}{ Fasting glucose } \\
\hline Model 1 & 1 & 1.03 & $0.86-1.24$ & 1.07 & $0.95-1.20$ & 0.99 & $0.85-1.14$ \\
\hline Model 2 & 1 & 0.98 & $0.82-1.19$ & 1.03 & $0.92-1.17$ & 0.98 & $0.85-1.13$ \\
\hline Model 3 & 1 & 0.96 & $0.80-1.16$ & 1.02 & $0.91-1.16$ & 0.99 & $0.86-1.15$ \\
\hline \multicolumn{8}{|c|}{ Metabolic syndrome } \\
\hline Model 1 & 1 & 1.03 & $0.83-1.27$ & 1.06 & $0.92-1.20$ & 1.01 & $0.85-1.19$ \\
\hline Model 2 & 1 & 1.01 & $0.81-1.25$ & 1.02 & $0.87-1.17$ & 0.99 & $0.84-1.17$ \\
\hline Model 3 & 1 & 1.01 & $0.81-1.26$ & 1.03 & 0.89-1.19 & 1.03 & $0.87-1.22$ \\
\hline \multicolumn{8}{|l|}{ Women } \\
\hline \multicolumn{8}{|c|}{ Waist circumference } \\
\hline Model 1 & 1 & 0.94 & $0.84-1.05$ & 1.00 & $0.92-1.08$ & 0.94 & $0.86-1.04$ \\
\hline Model 2 & 1 & 0.78 & $0.69-0.87$ & 0.88 & $0.81-0.95$ & 0.92 & 0.83-1.01 \\
\hline Model 3 & 1 & 0.79 & $0.70-0.90$ & 0.91 & 0.84-0.99 & 0.97 & $0.88-1.08$ \\
\hline \multicolumn{8}{|l|}{ Triglyceride } \\
\hline Model 1 & 1 & 1.10 & $0.96-1.27$ & 0.98 & $0.89-1.08$ & 0.91 & $0.81-1.03$ \\
\hline Model 2 & 1 & 0.97 & $0.84-1.12$ & 0.90 & $0.82-0.99$ & 0.90 & $0.80-1.03$ \\
\hline Model 3 & 1 & 0.98 & $0.85-1.13$ & 0.92 & $0.83-1.02$ & 0.93 & $0.82-1.05$ \\
\hline \multicolumn{8}{|l|}{ HDL cholesterol } \\
\hline Model 1 & 1 & 1.02 & $0.90-1.15$ & 0.95 & $0.88-1.04$ & 0.94 & $0.85-1.04$ \\
\hline Model 2 & 1 & 0.96 & $0.85-1.09$ & 0.92 & $0.85-1.01$ & 0.94 & $0.85-1.04$ \\
\hline Model 3 & 1 & 0.98 & $0.86-1.11$ & 0.96 & $0.88-1.09$ & 0.98 & $0.88-1.09$ \\
\hline \multicolumn{8}{|l|}{ Blood pressure } \\
\hline Model 1 & 1 & 1.15 & $1.02-1.30$ & 1.02 & $0.93-1.11$ & 0.84 & $0.75-0.93$ \\
\hline Model 2 & 1 & 0.98 & $0.86-1.12$ & 0.93 & $0.85-1.02$ & 0.83 & $0.74-0.93$ \\
\hline
\end{tabular}


Table 3 Odds ratios $(95 \% \mathrm{Cls})$ for metabolic syndrome and the individual components according to rice-eating patterns and gender (Continued)

\begin{tabular}{|c|c|c|c|c|c|c|c|}
\hline Model 3 & 1 & 1.01 & $0.89-1.15$ & 0.96 & $0.88-1.05$ & 0.86 & $0.77-0.97$ \\
\hline \multicolumn{8}{|c|}{ Fasting glucose } \\
\hline Model 1 & 1 & 0.91 & $0.79-1.05$ & 0.97 & $0.88-1.07$ & 0.90 & $0.80-1.02$ \\
\hline Model 2 & 1 & 0.84 & $0.72-0.97$ & 0.92 & 0.83-1.02 & 0.90 & 0.80-1.02 \\
\hline Model 3 & 1 & 0.83 & $0.71-0.96$ & 0.94 & $0.85-1.04$ & 0.91 & $0.80-1.04$ \\
\hline \multicolumn{8}{|c|}{ Metabolic syndrome } \\
\hline Model 1 & 1 & 1.04 & $0.90-1.20$ & 1.00 & $0.90-1.10$ & 0.83 & 0.73-0.94 \\
\hline Model 2 & 1 & 0.87 & $0.74-1.00$ & 0.89 & $0.80-0.99$ & 0.82 & $0.72-0.94$ \\
\hline Model 3 & 1 & 0.89 & $0.76-1.04$ & 0.93 & $0.84-1.04$ & 0.87 & $0.75-0.99$ \\
\hline
\end{tabular}

Model 1 : Not adjusted, Model 2 : adjusted for age and total energy intake, Model 3 : adjusted for age, total energy, education level, supplement use, exercise, drinking, and smoking.

Metabolic syndrome was defined as the presence of $\geq 3$ of 5 components.

The one of main characteristics of Korean diet is high proportion of carbohydrate intake because rice is the staple food. Korean eats rice only or with other foods such as beans or other grains. White rice can be characterized as a refined grain because it is polished during processing and the bran and germ are entirely removed. The rice with beans group showed some features of bean consumption, and the rice with multi-grains group showed the benefits of whole grain. The third Korea National Health and Nutrition Examination Survey (KNHANES III) reported grains such as barely, sorghum, glutinous rice, Job's tears, oats, millet and glutinous millet [9].

We found reduced risks for central obesity, dyslipidemia, and MetS in participants in the rice with multigrains group compared with those in the white rice

Table 4 Multivariate adjusted odds ratios ( $95 \% \mathrm{Cls}$ ) for metabolic syndrome and individual components of metabolic syndrome according to rice-eating patterns in women

\begin{tabular}{|c|c|c|c|c|c|c|c|}
\hline \multirow{3}{*}{$\begin{array}{l}\text { Metabolic syndrome } \\
\text { traits }\end{array}$} & \multirow{3}{*}{$\begin{array}{l}\text { White rice group } \\
\text { Ref }\end{array}$} & \multicolumn{4}{|c|}{ Rice with other foods group } & \multicolumn{2}{|c|}{ Mixed group } \\
\hline & & \multicolumn{2}{|c|}{ Rice with beans } & \multicolumn{2}{|c|}{ Rice with multi-grains } & \multirow[b]{2}{*}{ OR } & \multirow[b]{2}{*}{$95 \% \mathrm{Cl}$} \\
\hline & & OR & $95 \% \mathrm{Cl}$ & $\mathrm{OR}$ & $95 \% \mathrm{Cl}$ & & \\
\hline \multicolumn{8}{|l|}{ Postmenopausal women } \\
\hline Waist circumference & 1 & 0.78 & $0.66-0.92$ & 0.83 & $0.73-0.94$ & 0.88 & $0.75-1.03$ \\
\hline Triglyceride & 1 & 0.92 & $0.76-1.12$ & 0.88 & $0.77-1.02$ & 0.86 & $0.72-1.03$ \\
\hline HDL cholesterol & 1 & 0.90 & $0.76-1.08$ & 0.87 & $0.76-0.99$ & 0.82 & $0.70-0.97$ \\
\hline Blood pressure & 1 & 1.08 & $0.91-1.29$ & 1.00 & $0.88-1.14$ & 0.87 & $0.74-1.03$ \\
\hline Fasting glucose & 1 & 0.75 & $0.61-0.92$ & 0.92 & $0.80-1.07$ & 0.89 & $0.74-1.07$ \\
\hline Metabolic syndrome & 1 & 0.86 & $0.71-1.04$ & 0.85 & $0.73-0.98$ & 0.74 & $0.62-0.89$ \\
\hline \multicolumn{8}{|l|}{ Premenopausal women } \\
\hline Waist circumference & 1 & 0.77 & $0.64-0.93$ & 0.97 & $0.87-1.10$ & 1.02 & $0.89-1.17$ \\
\hline Triglyceride & 1 & 1.02 & $0.80-1.31$ & 0.95 & $0.81-1.12$ & 0.93 & $0.77-1.13$ \\
\hline HDL cholesterol & 1 & 1.03 & $0.85-1.24$ & 1.05 & 0.93-1.02 & 1.11 & $0.96-1.29$ \\
\hline Blood pressure & 1 & 0.90 & $0.73-1.11$ & 0.92 & $0.80-1.05$ & 0.86 & $0.73-1.01$ \\
\hline Fasting glucose & 1 & 0.93 & $0.74-1.18$ & 0.95 & $0.82-1.10$ & 0.97 & $0.81-1.17$ \\
\hline Metabolic syndrome & 1 & 0.88 & $0.66-1.17$ & 1.06 & $0.89-1.27$ & 1.03 & $0.83-1.28$ \\
\hline
\end{tabular}

Odds ratios were adjusted for age, total energy, education level, supplement use, exercise, drinking, and smoking.

The subjects with hormone replacement therapy were excluded among postmenopausal women.

Metabolic syndrome was defined as the presence of $\geq 3$ of 5 components. 
group. The rice with beans diet showed a beneficial effect on waist circumference and fasting glucose control. However, we could not find the BP lowering effect of rice with bean diet.

The most distinctive result was about central obesity. Means of WC of men in rice with multi-grains group and mixed group were higher than that of white rice group and odds ratio for central obesity was also elevated. However, means of $\mathrm{WC}$ in women were not significantly different among rice-eating groups, ORs for WC in rice with beans group and rice with multi-grains group were reduced. Especially in rice with beans group, both pre and post menopause women had low risk for central obesity.

We believe that the reduced ORs for MetS and the MetS components observed in rice with beans and multi-grains groups were the effect of soy protein and/ or isoflavones in the beans group and cereal fibers and various components of unpolished grains in the rice with multi-grains group. The presence of dietary fiber, vitamins and minerals, phenolic acid, and phytoestrogen may contribute to the protective effect of whole grains [27]. Whole grain intake is associated with a reduction in the risk for metabolic disease [28-31].

Soybean provides protein, fiber, and isoflavones. Clinical trials have shown positive effects of soy and soyfoods on total cholesterol, low-density lipoprotein (LDL) cholesterol, HDL cholesterol, and improvement in glycemic control [32-34]. Several studies have shown that soy isoflavones reduce the risk of coronary heart disease or cardiovascular disease by controlling blood lipid levels $[33,35,36]$.

The study had some unavoidable weaknesses. Because we use baseline data, this study had a limitation of a cross-sectional study. This kind of study cannot provide information of changes over time and explain the causal relationship between risk factor and outcome. However, as cohort study is going on, disease outcomes would be ascertained. It provides the chance to investigate the risk of not only long term effect of mass carbohydrate consumption but also dietary pattern related to sociopsychological tendency for health and diseases.

Food frequency questionnaire had a limitation of ingredient assuming [30]. We supposed that 'rice with multi grains' have whole grain effect but amount and kind of grains must be assumed in the 'rice with multi grains' item of food frequency questionnaire. The amount of beans was also estimated. These might have the association between diet and disease weakened.

The strength of this study was that metabolic risk factors were compared by rice-eating pattern in large scale data. And we could show the positive effects on health by rice eating with beans and multi-grains even in high carbohydrate consuming population.
We applied strict inclusion criteria in the present study to clearly identify the effect of rice-eating patterns on MetS. To avoid misclassification, the subjects themselves indicated their rice-eating patterns. It could clarify the feature of each pattern group. Furthermore, because disease may alter eating habits or lifestyle, we also excluded subjects with a diagnosis of a major disease. This reduces the available data but can make the effect of exposure in cross-sectional study relatively clearer.

The effect of rice-eating pattern on the metabolic components of MetS differed according to gender. We found a benefit of eating rice with beans or multi-grains in women; however, little difference in metabolic variables was observed among the rice-eating patterns in men. Because trends of nutrient intake by rice-eating pattern were similar in men and women (Table 2) and life-style factors were statistically controlled, gender difference of metabolic risks is due to intrinsic factor like hormone.

This finding is consistent with that of Kim et al. [26] who reported differences between men and women in their study on dietary carbohydrate and MetS, and with suggestion of Sun et al. [37] that genetic and/or hormonal influences may cause sexual dimorphism. Moreover, the effect of rice-eating patterns differed between preand postmenopausal women in the Kim et al. study [26]. The primary metabolic symptom in postmenopausal women is central obesity, which is likely associated with changes in the androgen-to-estrogen ratio after menopause [38]. Our results indicated that the beneficial effects of beans and multi-grains were the greatest in postmenopausal women, who lack protective hormones.

The results of this study suggested a desirable rice eating style. Rice is a main food in Asian countries and rice consumption is increasing in US [39]. Eating rice with beans or other grains can provide the variety on rice consumption and apply to increase whole grains consumption rather than refined grains as a partly replacement method in western countries.

\section{Conclusions}

The present study investigated the effects of rice-eating pattern on MetS indices in a large-scale data set. We conclude that eating rice with beans or multi-grains was associated with healthy effects and a reduction in metabolic risk factors, particularly in waist circumference and in postmenopausal women, although our findings reflect a relatively short-term effect on dietary habit. This study is a cross-sectional study. These results cannot explain the causal relationship of health effect by rice-eating patterns, prospective studies are needed. 


\section{Additional file}

Additional file 1: Appendix 1. Food list of food frequency

questionnaire used in Korean Genome and Epidemiology Study.

\section{Abbreviations}

BP: Blood Pressure; FFQ: Food Frequency Questionnaire; HDL cholesterol: High-Density Lipoprotein Cholesterol; KoGES: Korean Genome and Epidemiology Study; MetS: Metabolic Syndrome; OR: Odds Ratios; SBP: Systolic Blood Pressure; DBP: Diastolic Blood Pressure.

\section{Competing interests}

The authors declare that they have no competing interests.

\section{Author's contributions}

The author responsibilities were as follows - YA designed, initiated, developed analytic strategy, interpreted the results, and drafted the manuscript; SP and HK contributed to collection and analyzing the data, interpretation of results, and drafting of the manuscript. MK and KK contributed to preparation of data and interpretation of results; SSK designed and interpreted the results and was a principal investigator of this study. All authors read and reviewed the final manuscript.

\section{Acknowledgements}

We thank to the participants of Korean Genome and Epidemiology study. The present study was supported by the internal budgets of the Korea Centers for Disease Control and Prevention (2004-347-6111-213, 2005-3472400-2440-215, 2006-347-2400-2440-215)

\section{Author details}

${ }^{1}$ Division of Epidemiology and Health Index, Center for Genome Science, National Institute of Health, Center for Disease Control and Prevention, Chungcheongbuk-do, South Korea. 'Department of Preventive Medicine, College of Medicine, Hanyang University, Seoul, South Korea. ${ }^{3}$ Department of Preventive Medicine, Graduate School of Medicine, Gachon University, Incheon, South Korea.

Received: 13 April 2012 Accepted: 15 January 2013

Published: 22 January 2013

\section{References}

1. Reaven GM: Banting lecture Role of insulin resistance in human disease. Diabetes 1988, 1988(37):1595-1607.

2. Hanson RL, Imperatore G, Bennett PH, Knowler WC: Components of the "Metabolic Synrome" and incidenc of type 2 diabetes. Diabetes 2002, 51:3120-3127

3. Wilson PW, D'gostino RB, Parise H, Sullivan L, Meigs JB: Metabolic syndrome as a precursor of cardiovascular disease and type 2 diabetes mellitus. Circulation 2005, 112:3066-3072.

4. Resnick HE, Bardsley J, Foster GL, Ratner RE: Achievement of American Diabetes Association Clinical practice recommendations among US adult with diabetes, 1999-2002. Diabetes Care 2006, 29:531-537

5. Ford ES, Giles WH, Dietz WH: Prevalence of the metabolic syndrome among US adults: Findings from the third National Health and Nutrition Examination Survey. JAMA 2002, 287(3):356-359.

6. Azadbakht L, Mirmiran P, Esmaillzadeh A, Azizi F: Dairy consumption is inversely associated with the prevalence of the metabolic syndrome in Tehranian adults. Am J Clin Nutr 2005, 82(3):523-530.

7. Gu D, Reynolds K, Wu X, Chen J, Duan X, Reynolds RF, Whelton PK, He J, Inter ASIA Collaborative Group: Prevalence of the metabolic syndrome and overweight among adults in China. Lancet 2005, 365(9468):1398-1405.

8. Ervin RB: Prevalence of metabolic syndrome among adults 20 years of age and over, by sex, age, race and ethnicity and body mass index: United States 2003-2006. Natl Health Stat Report 2009, 5(13):1-7.

9. Korea Centers for Disease Control and Prevention: The report of the third Korea National Health and Nutrition Examination Survey (KNHANES III) 2005 - Nutrition survey (I). Seoul; 2006.

10. Groop L: Genetics of the metabolic syndrome. Br J Nutr 2000, 83(suppl): S39-S48.
11. Wolever TM: Dietary carbohydrates and insulin action in humans. $\mathrm{Br} J$ Nutr 2000, 83(suppl):S97-S102.

12. Poulsen P, Vaag A, Kyvik K, Beck-Nielsen H: Genetic versus environmental aetiology of the metabolic syndrome among male and female twins. Diabetologia 2001, 44:537-543.

13. Vega GL: Obesity, the metabolic syndrome and cardiovascular disease. Am Heart J 2001, 142:1108-1116.

14. Lidfeldt J, Nyberg P, Nerbrand C, Samsioe G, Schersten B, Agardh CD: Sociodemographic and Psychosocial factors are associated with features of the metabolic syndrome. The women's Health in the Lund Area (WHILA) study. Diabetes Obes Metab 2003, 5:106-112.

15. Ma Y, Li Y, Chiriboga DE, Olendzki BC, Hebert JR, Li W, Leung K, Hafner AR, Ockene I: Association between Carbohydrate Intake and Serum Lipids. J Am Coll Nutr 2006, 25(2):155-163.

16. Salmerón J, Manson JE, Stampfer MJ, Colditz GA, Wing AL, Willett WC: Dietary Fiber, Glycemic Load, and Risk of Non-insulin-dependent Diabetes Mellitus in Women. JAMA 1997, 277:472-477.

17. Ahn Y, Lee JE, Paik HY, Lee HK, Jo I, Kimm K: Development of a Semiquantitative Food Frequency Questionnaire based on dietary data from the Korea National Health and Nutrition Examination Survey. Nutr Sci 2003, 6(3):173-184

18. Ahn Y, Kwon E, Shim JE, Park MK, Joo Y, Kimm K, Park C, Kim DH: Validation and reproducibility of food frequency questionnaire for Korean genome epidemiologic study. Eur J Clin Nutr 2007, 61(12):1435-1441.

19. The Korean Nutrition Society (Ed): Food Value database. Seoul; 2009.

20. Park MK, Song YJ, Joung H, Li S, Paik HY: Establishment of an isoflavone database for usual Korean foods and evaluation of isoflavone intake among Korean children. Asia Pac J Clin Nutr 2007, 16(1):129-139.

21. Foster-Powell K, Holt SH, Brand-Miller JC: International table of glycemic index and glycemic load values. Am J Clin Nutr 2002, 7:615-6156.

22. The University of Sydney: Glycemic index and Gl database. http://www. glycemicindex.com.

23. Lee JS: Blood glucose response to some cereals and determination of their glycemic index to rice as standard food. Korean J Nutr 1997, 30:1170-1179

24. National Cholesterol Education Program (NCEP) Expert Panel on Detection Evaluation, and Treatment of High Blood Cholesterol in Adults (Adult Treatment Panel III): The Third Report of the National Cholesterol Education Program (NCEP) Expert Panel on Detection, Evaluation, and Treatment of High Blood Cholesterol in Adults (Adult Treatment Panel III) final report. Circulation 2002, 106:3143-3421.

25. World health Organization Western Pacific Region (WHO-WPR, The International Association for the Study of Obesity (IASO), the International Obesity Task Force(IOTF): The Asia-Pacific Perspective: redefining Obesity and its treatment. Australia Pty: Health Communications; 2000.

26. Kim K, Yun SH, Choi BY, Kim MK: Cross-sectional relationship between dietary carbohydrate, glycemic index, glycaemic load and risk of the metabolic syndrome in a Korean population. Br J Nutr 2008, 100(3):576-584

27. Slavin J, Martini MC, Jacobs DR Jr, Marquart L: Plausible mechanisms for the protectiveness of whole grains. Am J Clin Nutr 1999, 70(suppl):459s-463s.

28. Liese AD, Roach AK, Sparks KC, Marquart L, D'Agostino RB Jr, Mayer-Davis EJ: Whole-grain intake and insulin sensitivity: the Insulin Resistance Atherosclerosis Study. Am J Clin Nutr 2003, 78:965-971.

29. Esmaillzadeh A, Mirmiran P, Azizi F: Whole-grain intake and the prevalence of hypertriglyceridemic waist phenotype in Tehranian adults. Am J Clin Nutr 2005, 81(1):55-63.

30. McKeown NM, Saltzman E, Meigs JB, Wilson PWF, Liu S, Jacques PF: Carbohydrate nutrition, insulin resistance, and the prevalence of the metabolic syndrome in the Framingham Offspring Cohort. Diabetes Care 2004, 27(2):538-546.

31. Sahyoun NR, Jacques PF, Zhang XL, Juan W, McKeown NM: Whole-grain intake is inversely associated with the metabolic syndrome and mortality in older adults. Am J Clin Nutr 2006, 83(1):124-131.

32. Jenkins DJ, Kendall CW, Jackson CJ, Connelly PW, Parker T, Faulkner D Vidgen E, Cunnane SC, Leiter LA, Josse RG: Effects of high- and lowisoflavone soyfoods on blood lipids, oxidized LDL, homocysteine, and blood pressure in hyperlipidemic men and women. Am J Clin Nutr 2002, 76(2):365-372

33. Azadbakht L, Kimiagar M, Mehrabi Y, Esmaillzadeh A, Padyab M, Hu FB, Willett WC: Soy inclusion in the diet improves features of the metabolic 
syndrome: a randomized crossover study in postmenopausal women. Am J Clin Nutr 2007, 85(3):735-741.

34. Welty FK, Lee KS, Lew NS, Zhou JR: Effect of Soy Nuts on Blood Pressure and Lipid Levels in Hypertensive, Prehypertensive, and Normotensive Postmenopausal Women. Arch Intern Med 2007, 167:1060-1067.

35. Merz-Demlow BE, Duncan AM, Wangen KE, Xu X, Carr TP, Phipps WR, Kurzer MS: Soy isoflavones improve plasma lipids in normocholesterolemic, premenopausal women. Am J Clin Nutr 2000, 71:1462-1469.

36. Merritt JC: Metabolic syndrome: soybean foods and serum lipids. J Natl Med Assoc 2004, 96(8):1032-1041.

37. Sun SS, Sabo R, Arslanian S, Wu R, Sabo C: Age variation and sexual dimorphism in the sixteen diagnostic clusters of risk factors for the metabolic syndrome. J Public Health 2012, 20:487-497.

38. Polotsky HN, Polotsky AJ: Metabolic implications of menopause. Semin Reprod Med 2010, 28(5):426-434.

39. Batres-Marquez SP, JenSen HH, Upton J: Rice consumption in the United States: Recent evidence from food consumption surveys. J Am Diet Assoc 2009, 109:1719-1727.

doi:10.1186/1471-2458-13-61

Cite this article as: Ahn et al:: Rice-eating pattern and the risk of metabolic syndrome especially waist circumference in Korean Genome and Epidemiology Study (KoGES). BMC Public Health 2013 13:61.

\section{Submit your next manuscript to BioMed Central and take full advantage of:}

- Convenient online submission

- Thorough peer review

- No space constraints or color figure charges

- Immediate publication on acceptance

- Inclusion in PubMed, CAS, Scopus and Google Scholar

- Research which is freely available for redistribution 